\title{
A Series of Systematic Reviews on the Treatment of Acute Spinal Cord Injury: A Foundation for Best Medical Practice
}

\author{
Michael G. Fehlings, David W. Cadotte, and Lauren N. Fehlings
}

\begin{abstract}
The treatment of acute spinal cord injury (SCI) is a multidisciplinary effort that spans from the time of injury through to an acute care center, and in some cases the remainder of the individual's life. Recovery from SCI depends on the care received at each point along this spectrum in time. In order to facilitate the practice of evidence-based medicine and best clinical practices, a multidisciplinary team of clinicians and researchers systematically reviewed the literature on SCI and set out to answer pertinent clinical questions and establish evidence-based recommendations. This article introduces the series of systematic reviews, summarizes the most notable findings, and gives an overview of the questions asked in each review and the evidence-based recommendations for care. Some of the most important recommendations are as follows: (1) Patients should be immobilized before transport to a hospital using a cervical collar, head immobilization, and a spinal board; (2) MRI is strongly recommended for the prognostication of acute SCI; (3) early surgical intervention (from 8-24h) should be considered following acute traumatic SCI; (4) SCI patients are at significant risk of cardiovascular and respiratory problems and management should proactively anticipate these potential complications; and (5) outcomes can be improved by management in specialized centers with access to intensive care.
\end{abstract}

\section{Introduction}

$\mathrm{T}$ HE TREATMENT OF SPINAL CORD INJURY (SCI) spans multiple disciplines ranging from pre-hospital immobilization to surgical care to rehabilitation strategies. In some cases, persons suffering from SCI will be dependent on medical practitioners for the duration of their life. This series of systematic reviews aims to establish a set of best medical practice recommendations, formulated by integrating clinical expertise and evidence available from published literature (Sackett et al., 1996). Our objective is to engage those involved in the treatment of SCI to both evaluate the current state of health care delivery and discover opportunities for improvement.

Advances in the care of SCI patients at any point along the spectrum from pre-hospital stabilization to long-term rehabilitation offer a great opportunity to improve the quality and duration of a person's life. Identifying inconsistencies and integrating advances along this spectrum of care will certainly benefit the long-term outcome of persons suffering from SCI. This series of reviews not only integrates all aspects of this spectrum with regard to the published literature, but also incorporates the clinical expertise of health professionals. The recommendations reflect aspects of care that demonstrate evidence-based benefit to patients. The authors of the sys- tematic reviews also point out opportunities for future research in areas where evidence is lacking. Consensus expert opinion is provided where the evidence is emerging.

Highly-cited works in acute SCI have largely focused on the fundamental science underlying this devastating condition, with a relative paucity of highly-cited works that directly address the application of these therapies to patients (Furlan and Fehlings, 2006). In 2007, experts gathered at the SCITranslational Research Network in Toronto and developed a list of the most clinically-relevant issues in acute care for SCI that had not been recently reviewed (Furlan et al., 2010d). Members of the Rick Hansen Institute acute care and practice team, which is a multidisciplinary team consisting of researchers and clinicians across Canada, took this list and conducted a series of systematic reviews. The goal of this project was to develop a set of best practices and recommendations to help translate evidence into clinical practice.

The systematic reviews cover the spectrum of acute care, including pre-hospital care, the role of specialized centers of care, assessments of impairment and disability, the role of MRI, the timing of surgery, pediatric SCI, predictors of outcome, deep-vein thrombosis and nutrition management, special cardiopulmonary needs, and the role of therapies for acute SCI. Promising scientific research was also reviewed, as these pre-clinical and experimental treatments may become

Department of Neurosurgery, University of Toronto, Toronto, Ontario, Canada. 


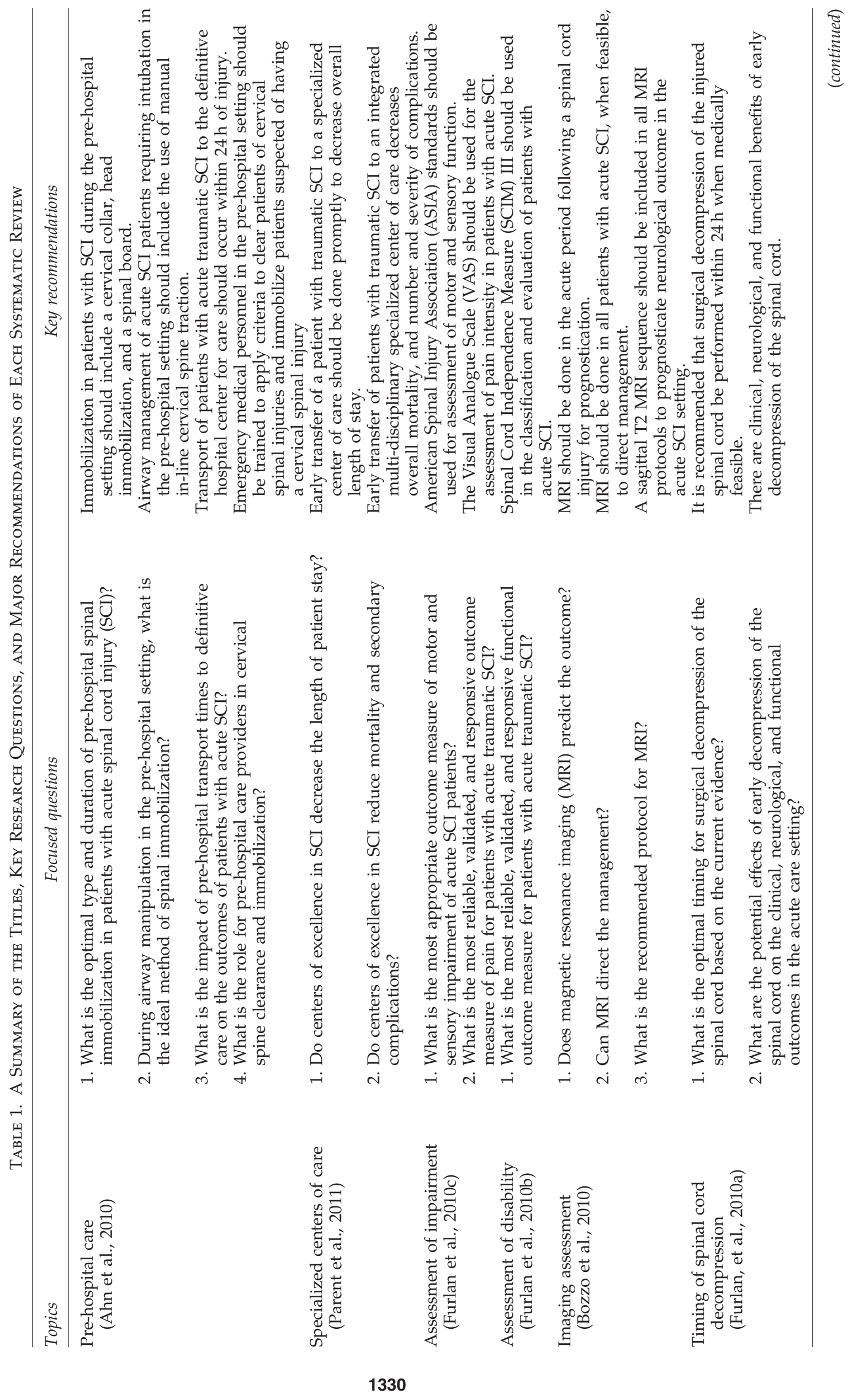




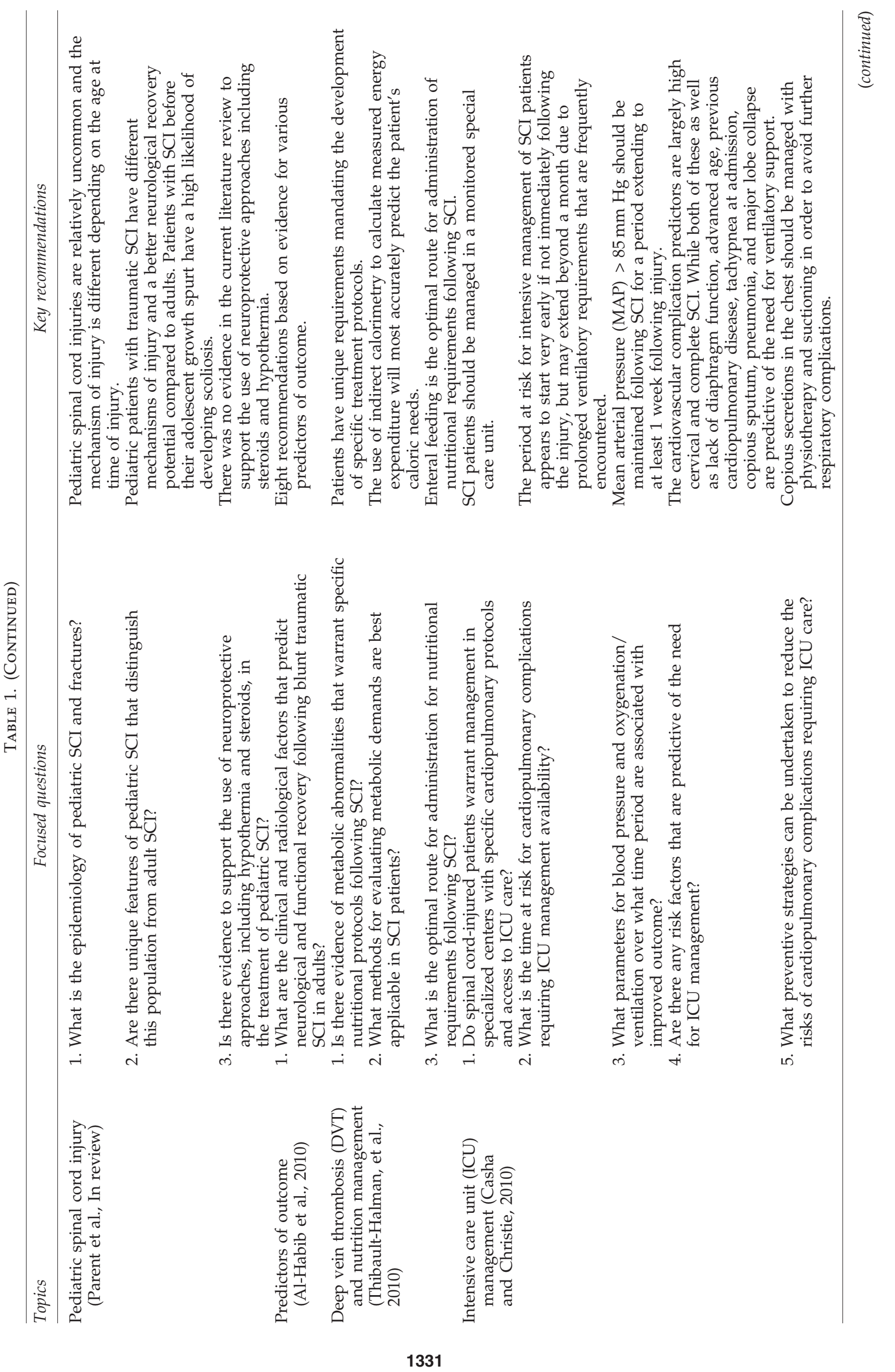




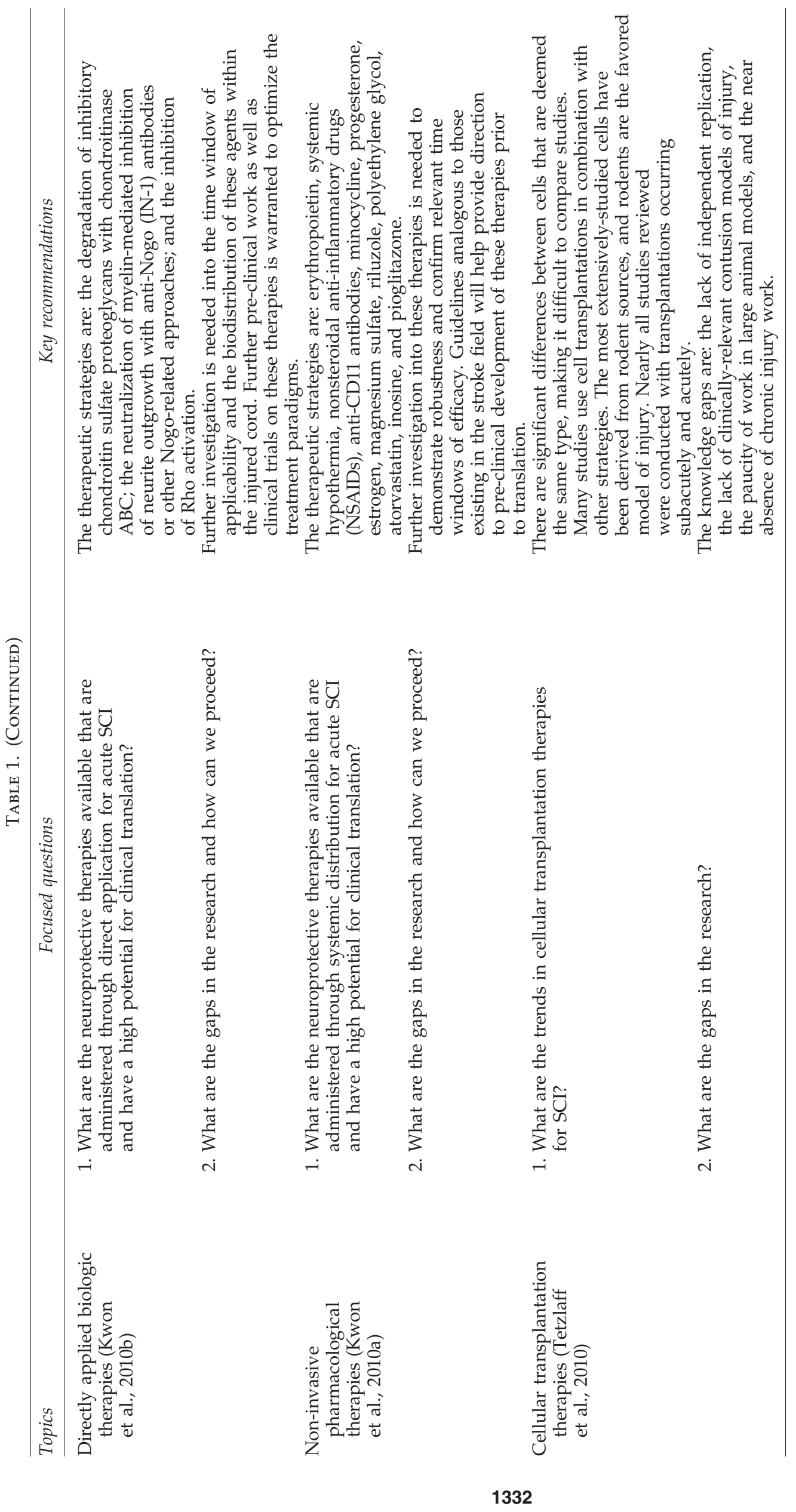


the next standard of care for SCI. From these reviews, the authors, in conjunction with an expert panel, established a set of recommendations (Table 1). Some of the most notable recommendations are as follows:

- Patients should be immobilized before transport to a hospital using a cervical collar, head immobilization, and a spinal board (Ahn et al., 2010).

- MRI is strongly recommended for the prognostication of acute SCI (Bozzo et al., 2010).

- Early surgical intervention (from 8-24h) should be considered following acute traumatic SCI (Furlan et al., 2010a).

SCI patients are at significant risk of cardiovascular and respiratory problems. Outcomes can be improved by management in specialized centers with access to intensive care facilities with specific protocols established for the management of SCI (Casha and Christie, 2010).

The overarching goal of this project is to increase the quality of care for people with SCI, and to ensure the uniform implementation of best practices. With these results, doctors and other health care professionals will be better equipped to provide the best care for their patients.

\section{Author Disclosure Statement}

No conflicting financial interests exist.

\section{References}

Ahn, H., Singh, J., Nathens, A., Macdonald, R.D., Travers, A., Tallon, J., Fehlings, M., and Yee, A. (2010). Pre-hospital care management of a potential spinal cord injured patient: A systematic review of the literature and evidence-based guidelines. J Neurotrauma.

Al-Habib, A.F., Attabib, N., Ball, J., Bajammal, S., Casha, S., and Hurlbert, R.J. (2010). Clinical predictors of recovery after blunt spinal cord trauma: Systematic review. J. Neurotrauma [Epub ahead of print].

Bozzo, A., Marcoux, J., Radhakrishna, M., Pelletier, J., and Goulet, B. (2010). The role of magnetic resonance imaging in the management of acute spinal cord injury. J. Neurotrauma [Epub ahead of print].

Casha, S., and Christie, S. (2010). A systematic review of intensive cardiopulmonary management after spinal cord injury. J. Neurotrauma [Epub ahead of print].

Furlan, J.C., and Fehlings, M.G. (2006). A Web-based systematic review on traumatic spinal cord injury comparing the "citation classics" with the consumers' perspectives. J. Neurotrauma 23, 156-169.

Furlan, J.C., Noonan, V., Cadotte, D.W., and Fehlings, M.G. (2010a). Timing of decompressive surgery of spinal cord after traumatic spinal cord injury: An evidence-based examination of pre-clinical and clinical studies. J. Neurotrauma [Epub ahead of print].

Furlan, J.C., Noonan, V., Singh, A., and Fehlings, M.G. (2010b). Assessment of disability in patients with acute traumatic spinal cord injury: A systematic review of the literature. J. Neurotrauma [Epub ahead of print].

Furlan, J.C., Noonan, V., Singh, A., and Fehlings, M.G. (2010c). Assessment of impairment in patients with acute traumatic spinal cord injury: A systematic review of the literature. J. Neurotrauma [Epub ahead of print].

Furlan, J.C., Singh, J., Hsieh, J., and Fehlings, M.G. (2010d). Methodology of systematic reviews and recommendations. J. Neurotrauma [Epub ahead of print].

Kwon, B.K., Okon, E.B., Plunet, W., Baptiste, D., Fouad, K., Hillyer, J., Weaver, L.C., Fehlings, M.G., and Tetzlaff, W. (2010b). A systematic review of directly applied biologic therapies for acute spinal cord injury. J. Neurotrauma [Epub ahead of print].

Kwon, B.K., Okon, E., Hillyer, J., Mann, C., Baptiste, D., Weaver, L.C., Fehlings, M.G., and Tetzlaff, W. (2010a). A systematic review of non-invasive pharmacologic neuroprotective treatments for acute spinal cord injury. J. Neurotrauma [Epub ahead of print].

Parent, S., Barchi, S., Lebreton, M.A., Casha, S., and Fehlings, M. (2011). Specialized centers of care for SCI. J. Neurotrauma [Epub ahead of print].

Parent, S., Mac-Thiong, J.-M., Roy-Beaudry, M., Sosa, J.F., and Labelle. H. (In review). Spinal cord Injury in the pediatric population: a systematic review of the literature. J. Neurotrauma.

Sackett, D.L., Rosenberg, W.M., Gray, J.A., Haynes, R.B., and Richardson, W.S. (1996). Evidence based medicine: What it is and what it isn't. BMJ 312, 71-72.

Tetzlaff, W., Okon, E.B., Karimi-Abdolrezaee, S., Hill, C.E., Sparling, J.S., Plemel, J.R., Plunet, W.T., Tsai, E.C., Baptiste, D., Smithson, L.J., Kawaja, M.D., Fehlings, M.G., and Kwon, B.K. (2010). A systematic review of cellular transplantation therapies for spinal cord injury. J. Neurotrauma [Epub ahead of print].

Thibault-Halman, G., Casha, S., Singer, S., and Christie, S. (2010). Acute management of nutritional demands after spinal cord injury. J. Neurotrauma [Epub ahead of print].

Address correspondence to: Michael G. Fehlings, M.D., Ph.D., FRCSC, FACS Division of Neurosurgery and Neuroscience Program University of Toronto 399 Bathurst Street

Toronto, Ontario M5T 2S8, Canada

E-mail: michael.fehlings@uhn.on.ca 
